\title{
Decision Support System for Airlines Fleet Capacity Management
}

\author{
M. M. Mohie El-Din, N. I. Ghali, A. Sadek and A. A. Abouzeid \\ Department of Mathematics, Faculty of science, Al-Azhar University \\ Nasr City, Cairo 31884, Egypt
}

\begin{abstract}
This study developed a decision support system (DSS) to schedule EGYPTAIR airline decisions regarding purchasing, leasing, or disposing of aircraft over period of time based on passenger demand forecasting and all costs associated with operating fleet of aircraft, the study implemented on three routes on EGYPTAIR airlines.
\end{abstract}

\section{General Terms:}

Decision Support System.

\section{Keywords:}

Decision Support System, Fleet Planning, Aircraft replacement schedule, Dynamic Programming.

\section{INTRODUCTION}

Decision-making is the process of developing and analyzing alternatives to choice from the different available alternatives. Most decisions are made to solve a problem. Decisions are either programmed or non-programmed. Programmed decisions are repetitive or routine and can be solved through mechanical procedures, such as applying the rules to find the optimal solution. About 90 percent of management decisions are programmed. Nonprogrammed decisions are nonrecurring, and they are often made during crisis conditions, where specific procedures are not available. Using a programmed decisions require a decision support system that solve the problem and suggest the optimal decision. A decision support system (DSS) is a computer program application that analyzes business data and presents it so that business managers and organizations can make effective business decisions [4]. In airline field, one of the crucial factors deciding its profitability is the ability to match fleet capacity to passenger demand. Decisions about fleet capacity management are important and complex decisions for airlines as the aircraft fleet must not only serve current but also future demands. This decisions involve purchase, lease or dispose of aircraft. Decision Support System for Airlines is very important and valuable tool for decisions regarding expansions and reductions for fleet capacity which are achieved through aircraft purchase, lease or by disposing of the surplus aircraft. Past studies have investigated the issues in the context of fleet capacity problems, such as decisions on aircraft type, flight frequency[3]; [9] and optimal combinations of owned and leased capacity[5]. Re- searchers have studied fleet management problems at operational and tactical levels in addition to the strategic level[6]; [2]. There are a few literature available on replacement cost in relation to fleet capacity management over different periods, or for revenue loss associated with dynamic and cyclical demand. On the other hand Hsu et al. in [1] developed a stochastic dynamic programming model to optimize airline decisions that related to purchasing, leasing, or disposing of aircraft over time based on dynamic programming model. In this work an implementation for the model presented in [1] is applied to EGYPTAIR Airlines fleet capacity management to automatically schedule Decisions regarding purchasing, leasing or disposing of aircraft over a period of time. This study will discuss the different types of DSS, stochastic dynamic programming model to optimize airline decisions to get the optimal match between fleet capacity and passenger traffic by considering demand fluctuations. This paper is organized as follows: Section 2 introduce the fleet capacity cost function and how to use the stochastic dynamic programming model to determine the optimal replacement schedule. The Implemented DSS is discussed in section 3 Experimental results are presented in Section 4 Concluding remarks are given in Section 5

\section{PRELIMINARIES}

In this section, an introduction to the cost function and the stochastic dynamic programming model used in in this work is presented in brief. Cost function and stochastic dynamic programming model determine the decision cost and optimize decisions in each decision period in our Implemented DSS, respectively.

\subsection{Cost Function}

Consider an airline that operates various routes, with $R$ set of routes and $r$ representing a particular route, $r \in R$. Let $\mathrm{T}$ be the study period with $\mathrm{n}$ number of decision periods $t, t=0,1, \cdots, n$. The duration of the decision periods may vary from each other and from different routes due to different economic cycles.

Let $N_{q y m}^{B t}$ and $N_{q y m}^{L t}$ be the number of aircraft associated with replacement Decisions during period $t$, where the superscripts $B$ and $L$ represent the purchased and leased aircraft while, the subscripts $\mathrm{q}, \mathrm{y}$ and $\mathrm{m}$ represent the aircraft status as its type, remaining available years and mileage traveled, respectively. The remaining available years of an aircraft, $y$, is determined by its number of years of maximum usage, $Y$, and the age of the aircraft, $y^{\prime}$, such that $y=Y-y^{\prime}$ also $N_{q y m}^{B t}$ and $N_{q y m}^{L t}$ are integers. The proposed de- 
cision of whether the fleet being expanded or reduced in terms of aircraft being recruited or disposed of, is judged by the value of $N_{q y m}^{B t}$ and $N_{q y m}^{L t}$. When the variables $N_{q y m}^{B t}$ and $N_{q y m}^{L t}$ are positive, the airlines will decide to expand their fleet capacity through purchasing and/or leasing, and the numbers of suggested aircraft with status $(q, y, m)$ are $N_{q y m}^{B t}$ and $N_{q y m}^{L t}$ respectively. Otherwise, the optimal decision will result in a capacity reduction with negative values for $N_{q y m}^{B t}$ and $N_{q y m}^{L t}$. Since the number of disposed aircraft cannot be greater than the existing scale, the following inequalities hold.

$$
\begin{array}{lll}
E_{q y m}^{B t} \geq\left|N_{q y m}^{B t}\right| & \text { if } & N_{q y m}^{B t}<0, \\
E_{q y m}^{L t} \geq\left|N_{q y m}^{L t}\right| & \text { if } & N_{q y m}^{L t}<0 .
\end{array}
$$

Where $E_{q y m}^{B t}$ represent the total number of purchased aircraft with status $(q, y, m)$ at period $t$ and $E_{q y m}^{L t}$ represent the total number of leased aircraft with status $(q, y, m)$ at period $t$. Let $S_{t}$ be the set of all aircraft operated by the airline during period $t$,

$S_{t}=\left\{E_{q y m}^{B t}, E_{q y m}^{L t} \forall q, y, m\right\}, E_{q y m}^{B t}, E_{q y m}^{L t} \in I^{+} \cup\{0\}$. Let $d_{t-1}$ denote the set of aircraft recruited or disposed of at period $(t-1)$ and these aircraft will be operated at period $t, d_{t-1}=$ $\left\{N_{q y m}^{B(t-1)}, N_{q y m}^{L(t-1)}, \forall q, y, m\right\}, N_{q y m}^{B t}, N_{q y m}^{L t} \in I$ and $t=t=$ $0,1, \cdots, n$. So the fleet operated at period t, $S_{t}$ can be formulated as:

$$
\begin{gathered}
S_{t}=S_{t-1}+d_{t-1}, \quad t=0,1, \cdots, n . \\
E_{q y m}^{B t}=E_{q y m}^{B(t-1)}+N_{q y m}^{B(t-1)}, \quad t=0,1, \cdots, n \\
E_{q y m}^{L t}=E_{q y m}^{L(t-1)}+N_{q y m}^{L(t-1)} \quad t=0,1, \cdots, n
\end{gathered}
$$

Which show that the fleet capacity and composition of period $t$ are the result of the replacement decisions made at period $(t-1)$. Let $Q_{q}$ represent the capacity of aircraft type $q$ and let $K_{q y m}^{t r}$ be the total flight frequencies on route $r$ offered by the aircraft with status $(q, y, m)$ during period $t$. The number of seats on route $r$ during period $t, A_{r}^{t}$ can be calculated as:

$$
A_{r}^{t}=\sum_{\forall q} \sum_{\forall y} \sum_{\forall m} \delta_{q y m}^{t r} Q_{q}\left(E_{q y m}^{B t}+E_{q y m}^{L t},\right) K_{q y m}^{t r},
$$

where $\delta_{q y m}^{t r}=1$ if the aircraft with status (q,y,m)assigned to route $\mathrm{r}$ and $\delta_{q y m}^{t r}=0$ otherwise. Since every route is being served by at least one aircraft, so the following inequality is hold $\sum_{\forall q} \sum_{\forall y} \sum_{\forall m} \delta_{q y m}^{t r} \geq 1$. Also the airline may set an ideal load factor on each route, and then the minimized fleet capacity can be obtained. The realized fleet capacities on the routes, depending on the average load factor, must be equal to or larger than the forecasted demand of decision period $t, F_{r}^{t}$ which yields

$$
l_{r}^{t} A_{r}^{t} \geq F_{r}^{t} \quad \forall r,
$$

where $l_{r}^{t}$ denotes the average load factor on route $r$ during period t. Equations [5], 6) can be reformatted as :

$$
\sum_{\forall q} \sum_{\forall y} \sum_{\forall m} \delta_{q y m}^{t r} Q_{q}\left(E_{q y m}^{B t}+E_{q y m}^{L t}\right) K_{q y m}^{t r} \geq \frac{F_{r}^{t}}{l_{r}^{t}} .
$$

The fact that not all aircraft can be assigned to a flight due to factors such as maintenance and turnover accounts, should be considered in the aircraft utilization model. Let $B_{q}^{r}$ denote the block time of type $q$ aircraft on route $r$, including the time spent in various aircraft trip modes, and let $u_{q y m}^{t}$ represent the maximum possible utilization of the aircraft with status $(q, y, m)$ during period $t$. For all aircraft with different status, the total aircraft utilization must be less than or equal to the maximum possible utilization. In this study we use the relation of Teodorovic et al.[8], such as $\sum_{\forall q} \sum_{\forall y} \sum_{\forall m} B_{q}^{r} K_{q y m}^{t r} Q_{q} \leq \sum_{\forall q} \sum_{\forall y} \sum_{\forall m}\left(E_{q y m}^{B t}+E_{q y m}^{L t}\right) u_{q y m}^{t}$. For a specific aircraft type with status $(q, y, m)$ the inequality $\sum_{\forall r} B_{q}^{r} K_{q y m}^{t r} \leq u_{q y m}^{t}$ must be hold.

The direct operating costs are all those expenses associated with operating a fleet of aircraft, including depreciation costs, maintenance costs and flying costs. The depreciation costs means the reduction in the value of the existing fleet and its calculation based on the purchase or lease price of the aircraft. In some ways, the depreciation costs depend on the market demand when the aircraft is originally purchased or leased. For instance, when most airlines forecast an upward trend in future demand, the original purchase or lease cost will be high, resulting in a high depreciation cost. Let $P_{q y m}$ represent the average purchase cost for an aircraft with status $(q, y, m)$ at period $t$ also let $R_{q y m}^{t d}$ represent the average lease cost for an aircraft with status $(q, y, m)$ with total lease period $d$ at period $t$. The depreciation cost for the existing fleet at period $t$ can be formulated as

$$
\sum_{\forall q} \sum_{\forall y} \sum_{\forall m} E_{q y m}^{B t} P_{q y m} X_{g}^{t}+E_{q y m}^{L t} R_{q y m}^{t d} \quad \forall t
$$

Where $X_{g}^{t}$ denote the average remaining resale ratio of the original purchase price with average yearly interest rate $g$ of period $t$.

Maintenance cost can be divided into fixed maintenance cost and variable maintenance cost. Fixed maintenance costs represent the cost overhead such as maintenance of the building, equipment, land rental as well as head office. Variable maintenance costs which depend on the number of aircraft in the fleet and the aircraft status. The maintenance cost of period $t$ can be formulated as

$$
M_{t}+\sum_{\forall q} \sum_{\forall y} \sum_{\forall m} V_{q y m}^{t}\left(E_{q y m}^{B t}+E_{q y m}^{L t}\right) .
$$

Where $M_{t}$ represent the fixed maintenance costs(overhead) of period $t$ and $V_{q y m}^{t}$ represent the variable maintenance cost for aircraft of status $(q, y, m)$ at period $t$. The flying cost can be expressed as

$$
\sum_{\forall q} \sum_{\forall y} \sum_{\forall m} b_{q r}^{t} \delta_{q}^{r} K_{q y m}^{t r}
$$

where $b_{q r}^{t}$ represent the average flying cost of aircraft of type $q$ on route $r$. The total direct operating cost of the airline for operating the existing fleet during period $t, C_{D}^{t}$, can be formulated as

$$
\begin{aligned}
C_{D}^{t} & =\sum_{\forall q} \sum_{\forall y} \sum_{\forall m}\left(E_{q y m}^{B t} P_{q y m} X_{g}^{t}+E_{q y m}^{L t} R_{q y m}^{t d}\right. \\
& +V_{q y m}^{t}\left(E_{q y m}^{B t}+E_{q y m}^{L t}\right)+\sum_{\forall r} \sum_{\forall q} \sum_{\forall y} \sum_{\forall m} b_{q r}^{t} \delta_{q}^{r} K_{q y m}^{t r}+M^{t} .
\end{aligned}
$$

The total indirect operating cost as a result of serving passengers at period $t, C_{I}^{t}$ can be expressed as follows:

$$
C_{I}^{t}=\sum_{\forall r} F_{r}^{t} H^{r}
$$


Where $H^{r}$ represent the average indirect cost per passenger on route $r$. So the total operating cost of the airline on period $t$ $C^{t}=C_{D}^{t}+C_{I}^{t}$.

When disposing of a purchased aircraft, the airline will receive the salvage value of the aircraft, which is its remaining value after depreciation. The salvage value is inversely related to the age of the aircraft. When terminating the contract of a leased aircraft, the airline has to pay a penalty for returning the aircraft earlier than stipulated in the lease contract. The longer the remaining lease period, the higher the penalty will be. Moreover, both salvage value and penalty cost as a result of fleet reduction is dependent upon the demand for aircraft in the market. To calculate the replacement cost let $D_{q y m}^{t}, Z_{q y m}^{t e}, P_{q y m}^{t}$ and $Y_{q y m}^{t}$ represent the salvage value, the penalty with remaining lease period $e$, original purchase price and the total depreciation cost for an aircraft of status $(q, y, m)$ at period $t$, respectively. The replacement cost for disposing of an aircraft during period $t$ can be formulated as $\sum_{\forall q} \sum_{\forall y} \sum_{\forall m}\left|N_{q y m}^{B t}\right|\left(P_{q y m}^{t}-Y_{q y m}^{t}-D_{q y m}^{t}\right)$, where $\left|N_{q y m}^{B t}\right|$ represent the number of purchased aircraft suggested to be disposed of. The penalty cost for disposing of leased aircraft during period $t$ can be expressed as $\sum_{\forall q} \sum_{\forall y} \sum_{\forall m}\left|N_{q y m}^{L t}\right| Z_{q y m}^{t e}$, where $\left|N_{q y m}^{L t}\right|$ represent the number of leased aircraft suggested to be disposed of by terminating the contract. The total replacement cost can expressed as follows:

$$
\begin{aligned}
U^{t} & =\sum_{\forall q} \sum_{\forall y} \sum_{\forall m} \alpha_{q y m}^{t}\left|N_{q y m}^{B t}\right|\left(P_{q y m}^{t}-Y_{q y m}^{t}-D_{q y m}^{t}\right) \\
& +\sum_{\forall q} \sum_{\forall y} \sum_{\forall m} \beta_{q y m}^{t}\left|N_{q y m}^{L t}\right| Z_{q y m}^{t e} .
\end{aligned}
$$

Where $\alpha_{q y m}^{t}$ and $\beta_{q y m}^{t}$ are binary variables and its relations with the replacement decisions as follows:

$$
\left\{\begin{array}{lllll}
\alpha_{q y m}^{t}=1 & \text { if } & N_{q y m}^{B t}<0 & \text { else } & \alpha_{q y m}^{t}=0 \\
\beta_{q y m}^{t}=1 & \text { if } & N_{q y m}^{L t}<0 & \text { else } & \alpha_{q y m}^{t}=0 .
\end{array}\right.
$$

Due to the fluctuations in passenger demand, the actual demand may be underestimated, overestimated or be correct. Let $f_{r}^{t}$ be the actual passenger demand on route $r$ during period $t$. If the actual demand is less than the forecasted result, i.e. $f_{r}^{t}-F_{r}^{t}<0$, then the airline bears an increased total indirect operating cost for serving their passengers due to the unsold seats. The punishment associated with an overestimation is included in Equation (12). On the other hand there will be unsatisfied passengers due to insufficient fleet capacity if $f_{r}^{t}-F_{r}^{t} \geq 0$. Let $I_{r}^{t}$ represent the average revenue loss associated with one unit of insufficient seats on route $r$ during period $t$, which can be estimated by the average fare on the route. The penalty cost function due to the inaccurate forecast on route $r$ at period $t, p_{r}^{t}$, which can be formulated as

$$
p_{r}^{t}=\left(f_{r}^{t}-F_{r}^{t}\right) I_{r}^{t}
$$

The total penalty cost of the airline during period $t$ is $L^{t}=\sum_{\forall r} p_{r}^{t}$.

The total cost during period t, $Q^{t}$ which given by the operating cost, replacement cost and the penalty cost can be formulated as follows:

\subsection{Stochastic Dynamic Programming Model}

Section (2.1) formulates the cost function of the airline for single period. From Equations (2)-(4) we can conclude that the fleet operated during period $t$ is the result of the replacement decisions made at period $(t-1)$ and the fleet capacity during period $t$ is determined based on demand forecast at period $(t-1)$ towards period t. So the replacement decisions made and the demand forecast at period $(t-1)$. That is to say, the replacement decisions made and the demand forecast executed at period $(t-1)$ have a certain level of involvement with the operating cost, $C_{t}$, and the penalty cost, $L_{t}$, of period t. Similarly, the demand forecast result for period $(t+1)$ served as the reference of the replacement decisions made at period t, which resulted in the replacement cost, $U_{t}$ in Equation (13). These cost dependent relationships between decisions made at neighboring periods are explained as recursions, and are depicted graphically in Figure 1 by taking into consideration the demand fluctuation. The circular node represents the set of aircraft operated during period t, $S_{t}$, while the square node is the set of aircraft recruited or disposed of at period $t$ when the demand of period $(t+1)$ is forecasted as label $w, d_{t}^{w}$, respectively. As shown in Fig. 1 , the resulting fleet $S_{t}$ is the result of the decision made during period (t-1) with respect to different demand fluctuations labeled $w$. For a given period t, the airline makes the replacement decisions in accordance with the forecasted result for period $(t+1)$, the demand of period $(t+1)$. In other words, the total cost of period $(t+1)$, given by the sum of operating, replacement and penalty costs, is directly affected by the decision made at period $t$ and the forecasted demand for period $(\mathrm{t}+1)$

As for dynamic programming, the stage and the state in this study refer to decision period $\mathrm{t}$ and operating fleet $S_{t}$, respectively. Let $C^{t}\left(S^{t}, d^{t}\right)$ represent the total cost from period $\mathrm{t}$ forward, where $d^{t}$ denotes the replacement decision. Given $S^{t}$ and t, let $d_{*}^{t}$ denote any value of $d^{t}$ that minimizes $C^{t}\left(S^{t}, d^{t}\right)$, and let $C_{*}^{t}$ be the corresponding minimum value of $C^{t}\left(S^{t}, d^{t}\right)$. Then

$$
C_{*}^{t}\left(S^{t}\right)=\min _{d_{*}^{t}} C^{t}\left(S^{t}, d^{t}\right)=C^{t}\left(S^{t}, d_{*}^{t}\right) .
$$

In order to consider the stochastic feature of future demand even further, the minimum expected sum from period t forward, $C^{t}\left(S^{t}, d^{t}\right)$, given that the fleet and replacement decision in period $\mathrm{t}$ are $S^{t}$ and $d^{t}$, can be formulated as follows:

$$
\left.C_{(}^{t} S^{t}, d^{t}\right)=\sum_{w=1}^{3} p_{w}^{t}\left[Q^{t}+C^{t}\left(S^{t}, d_{*}^{t}\right)\right],
$$

where $C^{t}\left(S^{t}, d_{*}^{t}\right)=\min _{d^{t+1}} C^{t}\left(S^{t+1}, d^{t+1}\right)$ is the recursive relationship that identifies the optimal decision for period $(t+1)$, given that the optimal decision for period $(\mathrm{t}+2)$ has been made and $p_{w}^{t}$ is the probability of the forecasted passenger demand fluctuation labeled, $w$ at period $t$. The objective for the Decision Support System is to determine $\pi=\left[d^{1}, d^{2}, \ldots, d^{t}, \ldots, d^{T}\right]$ so as to

$$
\begin{gathered}
\min _{\pi} E\left(\sum Q^{t}\right) \\
\text { s.t. } \sum_{\forall q} \sum_{\forall y} \sum_{\forall m} \delta_{q}^{r} Q_{q}\left(E_{q y m}^{B t}+E_{q y m}^{L t}\right) K_{q y m}^{t r} \geq \frac{F_{r}^{t}}{l_{r}^{t}} \\
N_{q y m}^{B t} \text { and } N_{q y m}^{L t} \text { integers } \forall q, y, m \quad \forall t
\end{gathered}
$$




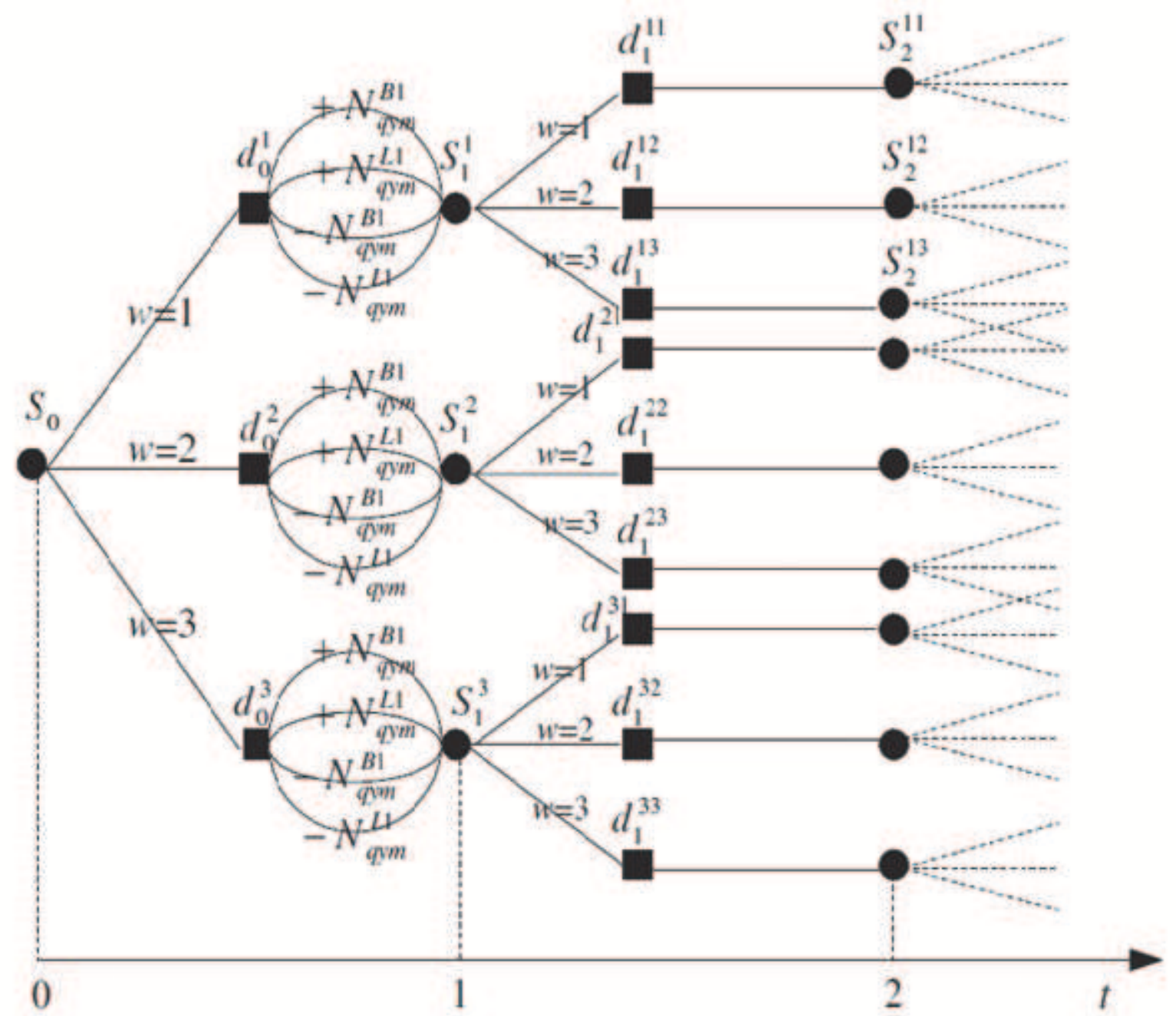

Fig. 1. A stochastic dynamic programming network.

The recursive relationship for the problem is $C_{*}^{t+1}\left(S^{t+1}\right)=$ $\min _{d^{t+1}} C^{t}\left(S^{t+1}, d^{t+1}\right)$. The optimal decision at period $t$ is found by solving by backwards induction starting at $t=n$ and using Equations $(18)$ at each step to find the optimal decision for the periods. The replacement decisions include when, how many, and how many different types of aircraft are to be recruited through lease or purchase, as well as when and which aircraft, leased and purchased, with various statuses are to be disposed of.Moreover, the duration of each period may be different for different city-pairs due to variations in the length and trend of the economic cycle. The fleet operating on the routes, depending on the average load factor, must be equal or larger than the forecasted demand of the period.

\section{DECISION SUPPORT SYSTEM}

There are many categories for DSS according to their primary driving source of information. Power in [7] suggested five different DSS known to be Data driven, Model driven, Knowledge driven, Document driven and Communication driven and group DSS descriped as follows:-
Data driven DSS includes file drawer and management reporting systems, data Warehousing and analysis systems, Executive Information Systems (EIS) and Geographic Information Systems (GIS). Data-Driven DSS emphasize access to and manipulation of large databases of structured data and especially a time-series of internal company data and some times external data. Model driven DSS includes systems that use accounting and financial models, representational models, and optimization models. Model-Driven DSS emphasize access to and manipulation of a model. Simple statistical and analytical tools provide the most elementary level of functionality. Some OLAP systems that allow complex analysis of data may be classified as hybrid DSS systems providing modeling, data retrieval and data summarization functionality. Model-Driven DSS use data and parameters provided by decision-makers to aid them in analyzing a situation, but they are not usually data intensive. Knowledge driven DSS can suggest or recommend actions to managers. These DSS are person computer systems with specialized problem solving expertise. The "expertise" consists of knowledge about a particular domain, understanding of problems within that domain, and "skill" at solving some of these problems. A related 


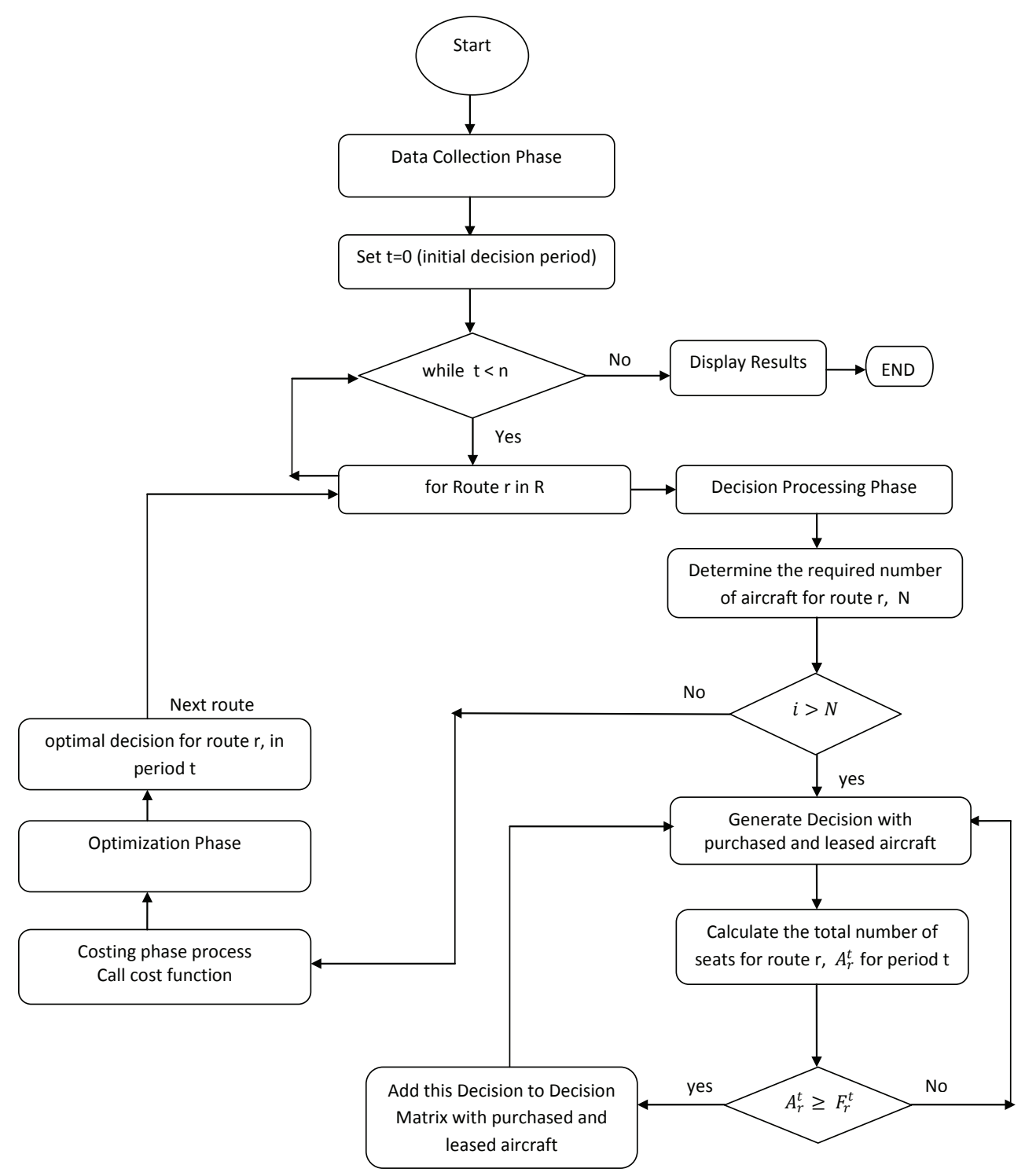

Fig. 2. Implemented DSS flowchart

concept is Data Mining. It refers to a class of analytical applications that search for hidden patterns in a database. Data mining is the process of sifting through large amounts of data to produce data content relationships. Data Mining tools can be used to create hybrid Data Driven and Knowledge Driven DSS. Document driven DSS integrates a variety of storage and processing technologies to provide complete document retrieval and analysis. The Web pro- vides access to large document databases including databases of hypertext documents, images, sounds and video. A search engine is a powerful decision-aiding tool associated with this type of DSS. Communication driven and group DSS where includes communication, collaboration and coordination focus on supporting groups of decision makers to analyze problem situations and performing group decision making tasks. 
In this study, an implementation for a Model driven presented in [1] is given aiming to help EGYPTAIR airline to make decisions regarding purchasing, leasing and disposing of their aircraft over a period of time which will construct the decision based on fleet cost function and the stochastic dynamic programming model mentioned before in sections 2.2 and 2.1 respectively.

Our implemented DSS is designed as the following phases:Data collection phase

All required data are collected for fleet capacity, aircrafts in the fleet and routes carried by the airline such as:-

-Aircraft type, age, mileage traveled and number of seats.

-Original price, purchase Date, average purchase price and salvage value for purchased aircraft.

-Average lease cost, contracted lease period and penalty cost/month for leased aircraft.

-Average maintenance cost for aircraft.

-Rout from, route to, assigned aircrafts, weekly flight frequencies, block time(hours), fare(EGP/person-trip), average flying costs/aircraft, average indirect costs/passenger, passenger actual demand and passenger demand forecasting for this routes .

\section{Decision processing phase}

In this phase we apply our algorithm to generate all possible decisions for specific route by matching the total number of seats offered by this route with passenger demand forecasting for the same route.

\section{Costing phase}

In this phase we call the cost function that calculate the cost for every decision in phase 3

\section{Optimization phase}

In this phase we apply the stochastic dynamic programming model to optimize the decisions and obtain the optimal decision. Fig. 2 represent the implemented DSS flowchart, where

$t$ : represent the decision period

$n:$ represent the total number of decision periods

$r$ : represent a specific route from the total set of routes $R$

$i$ : increment indicator

$A_{r}^{t}$ : represent the total number of seats for route $r$ at period $t$

\section{EXPERIMENTAL RESULTS}

This study further presents a case study to demonstrate applications of the DSS, based on available data from EGYPTAIR Airlines. For the sake of simplification, three cities in two countries were selected from all the cities currently being served by EGYPTAIR Airlines The three city-pairs (routes) are CAIRO (CAI)-LONDON(LON),-JEDDAH (JED), -RIYADH (RUH). There are 10 wide-body aircraft including 3 Airbus A320300, 2 Airbus A340-200, 3 Boeing B737-800 and 2 Boeing B777200 flying on different routes served by the company. Table 1 Table 2 and Table 3 list the basic data of the fleet, the aircraft in the fleet and the supply parameters for the routes as related to aircraft type, frequencies, block time and fares, respectively. The study period totals one year, from 01/07/2013 to 30/06/2014. Table 4 shows the optimal replacement decisions made in the first period, including the duration of the decision periods and the fleet compositions. In the present study, the airline serves the routes entirely with all leased aircraft because that way the airline is exempt from the high depreciation cost and only needs to pay the lease cost. However, high maintenance cost places a heavy financial burden on the airline when the aircraft become older and have high mileage. When that happens, the airline may prefer to purchase rather than lease these older aircraft since the flexibility of leasing may not compensate for the high maintenance cost.

\section{CONCLUSIONS}

This paper presents a Decision Support System(DSS) for EGYPTAIR Airlines fleet schedule. The company have gained new insight and ideas on how to improve the fleet scheduling. It supports EGYPTAIR planners with the following characteristics:-

- determine the optimal decision for Purchasing/Leasing or disposing of the aircraft over a period of time

- determine when and how many different types of aircrafts are to be recruited through lease or purchase

- when and which aircraft, leased and purchased, with various statuses are to be disposed of.

Moreover, the duration of each period may be different for different city-pairs due to variations in the length and trend of the economic cycle. The implemtation of the system is illustrated with a case study involving EGYPTAIR airlines. It was found that EGYPTAIR tends to lease A330-300 instead of A340-200 aircraft to match the passenger demands on route CAI-LON to reduce costs. In addition, the total cost for a particular decision period can be minimized by providing a perfect match of the forecasted demand with the actual demand, instead of overestimated or underestimated forecasts that will lead to increased costs.

\section{ACKNOWLEDGMENT}

The authors would like to thank the EGYPTAIR Airlines Company for supporting this research by providing all required data to implement our proposed system also we thank Prof.Dr.Hassan Mohamed Serag, the dean of faculty of science, Al Azhar University for supporting the research.

\section{REFERENCES}

[1] Hsu, C.-I., Li, H.-C., Liu, S.-M., Chao, C.-C.,2011. Aircraft replacement scheduling: A dynamic programming approach.Transportation Research Part E 47, 41-60.

[2] Jin, D., Kite-Powell, H.L., 2000. Optimal fleet utilization and replacement. Transportation Research Part E 36, 3-20.

[3] Kanafani, A., Ghobrial, A., 1982. Aircraft evaluation in air network planning. Transportation Engineering Journal of ASCE $108,282-300$.

[4] Kopackova, H. and Skrobackova, M. 2006. Decision Support System or Business Intelligence:what can help in decision making?, Scientific Papers of the University of Pardubice, Series D, Faculty of Economics and Administration, vol.10:1, 98103.

[5] Oum, T.H., Zhang, A., Zhang, Y., 2000. Optimal demand for operating lease of aircraft. Transportation Research Part B 34, 17-29.

[6] Powell, W.B., Carvalho, T.A., 1997. Dynamic control of multicommodity fleet management problems. European Journal of Operational Research 98, 522-541.

[7] Power, D.J. 2002. Decision support systems: Concepts and resources for managers. Westport, Connecticut: Quorum Books.

[8] Teodorovic, D., Kalic, M., Pavkovic, G., 1994. The potential for using fuzzy set theory in airline network design. Transportation Research 28, 103-121. 
Table 1. Basic Data of the fleet

\begin{tabular}{|c|c|c|c|c|}
\hline Aircraft Type & Number & $\begin{array}{c}\text { Average Capacities } \\
\text { (Numbers of Seat) }\end{array}$ & $\begin{array}{c}\text { Average Age } \\
\text { (Year) }\end{array}$ & $\begin{array}{c}\text { Number of Purchased } \\
\text { and Leased aircrafts } \\
\text { (Purchased/Leased) }\end{array}$ \\
\hline A330-300 & 3 & 268 & 9.2 & $0 / 3$ \\
\hline A340-200 & 2 & 260 & 17.5 & $0 / 2$ \\
\hline B737-800 & 3 & 104 & 22.4 & $0 / 3$ \\
\hline B777-200 & 2 & 319 & 12.9 & $0 / 2$ \\
\hline
\end{tabular}

Table 2. Basic data of aircrafts in the fleet

\begin{tabular}{|c|c|}
\hline Leased Aircraft & Average Lease Cost Per Month(EGP) \\
\hline A330-300 & 3785200 \\
\hline A340-200 & 619780 \\
\hline B737-800 & 8114500 \\
\hline B777-200 & 626700 \\
\hline
\end{tabular}

[9] Teodorovic, D., Krcmar-Nozic, E., 1989. Multicriteria model to determine flight frequencies on an airline network under competitive conditions. Transportation Science 23, 14-25. 
Table 3. Parameter values related to routes

\begin{tabular}{|c|c|c|c|c|c|}
\hline Route & Aircraft Type & $\begin{array}{c}\text { Weekly flight } \\
\text { frequencies }\end{array}$ & $\begin{array}{c}\text { Block Time } \\
\text { (hours) }\end{array}$ & $\begin{array}{c}\text { Fare(EGP/Person- } \\
\text { trip) }\end{array}$ & Load factor \\
\hline CAI-LON & A330-300,B737-800 & 2 & 7167.384 & 2295 & 0.61 \\
\hline CAI-JED & A330-300,A340-200, & 9 & 10207.516 & 1421 & 0.69 \\
\hline B737-800,B777-300 & & 6324.162 & 1537 & 0.69 \\
\hline
\end{tabular}

Table 4. The optimal purchase and replacement decisions made in the first period

\begin{tabular}{|c|c|c|c|c|c|c|c|c|}
\hline \multirow{3}{*}{ Route } & \multicolumn{5}{|c|}{ the first period, $\mathrm{t}=1$} & \multicolumn{3}{|c|}{ the second period, $\mathrm{t}=2$} \\
\hline & \multirow[t]{2}{*}{ Duration } & \multicolumn{2}{|c|}{ Fleet Composition } & \multicolumn{2}{|c|}{$\begin{array}{c}\text { Purchase and } \\
\text { Replacement Decisions }\end{array}$} & \multirow[t]{2}{*}{ Duration } & \multicolumn{2}{|c|}{ Fleet Composition } \\
\hline & & $\begin{array}{l}\text { Aircraft } \\
\text { Type }\end{array}$ & Number & $\begin{array}{l}\text { Aircraft } \\
\text { Type }\end{array}$ & Number & & $\begin{array}{l}\text { Aircraft } \\
\text { Type }\end{array}$ & Number \\
\hline \multirow{2}{*}{ CAI-LON } & $2014-$ & A330-300 & 1 & A330-300 & 1(Leasing) & $2015-$ & A330-300 & 2 \\
\hline & 2015 & B737-800 & 1 & - & - & 2016 & B737-800 & 1 \\
\hline \multirow{4}{*}{ CAI-JED } & & A330-300 & 1 & A330-300 & - & \multirow{4}{*}{$\begin{array}{l}2015- \\
2016\end{array}$} & A330-300 & 1 \\
\hline & & A $340-200$ & 1 & A $340-200$ & ـ & & A $340-200$ & 1 \\
\hline & 2014- & B737-800 & 1 & B737-800 & - & & B737-800 & 1 \\
\hline & & B777-300 & 1 & B777-300 & - & & B737-800 & 1 \\
\hline \multirow{4}{*}{ CAI-RUH } & & A330-300 & 1 & A330-300 & - & \multirow{4}{*}{$\begin{array}{l}2015- \\
2016\end{array}$} & A330-300 & 1 \\
\hline & & A $340-200$ & 1 & A340-200 & - & & A $340-200$ & 1 \\
\hline & 2014- & B737-800 & 1 & B737-800 & - & & B737-800 & 1 \\
\hline & & B777-300 & 1 & B777-300 & - & & B777-300 & 1 \\
\hline
\end{tabular}

